\title{
IKK $\beta$ and the anti-adipogenic effect of platelet-derived growth factor in human abdominal subcutaneous preadipocytes
}

\author{
AnneMarie Gagnon ${ }^{1,2}$, Anne Landry ${ }^{1,2}$ and Alexander Sorisky, \\ ${ }^{1}$ Chronic Disease Program, Ottawa Health Research Institute, 725 Parkdale Avenue, Ottawa, Ontario, Canada K1Y 4E9 \\ ${ }^{2}$ Departments of Medicine and of Biochemistry, Microbiology and Immunology, University of Ottawa, 451 Smyth Road, Ottawa, Ontario, Canada K1H 8M5 \\ (Correspondence should be addressed to A Sorisky; Email: asorisky@ohri.ca)
}

\begin{abstract}
To clarify how anti-adipogenic factors act on preadipocytes to inhibit their differentiation, we compared preadipocyte signaling responses generated by platelet-derived growth factor (PDGF; anti-adipogenic) versus insulin (pro-adipogenic). PDGF, but not insulin, stimulated the phosphorylation of inhibitor of $\kappa \mathrm{B}$ kinase $\beta$ (IKK $\beta$ ) in a time-dependent manner. This PDGF-dependent phosphorylation event was inhibited by $60 \%(P<0 \cdot 05)$ when the cells were pretreated with wortmannin, indicating a requirement for the phosphatidylinositol (PI) 3-kinase/AKT pathway. IKK $\beta$ phosphorylation by PDGF was neither accompanied by $\mathrm{I} \kappa \mathrm{B} \alpha$
\end{abstract}

degradation nor NF- $\kappa \mathrm{B}$ activation. PDGF inhibited human adipocyte differentiation, assessed by triacylglycerol accumulation $(75 \%$ reduction; $P<0 \cdot 01)$ and by fatty acid synthase protein expression (60\% reduction; $P<0 \cdot 05$ ); these responses were no longer apparent in the presence of sc-514, a selective inhibitor of IKK $\beta$. Our data describe a novel PDGF response in human preadipocytes that involves the pro-inflammatory kinase IKK $\beta$ and demonstrate that it is required for the inhibition of adipogenesis.

Journal of Endocrinology (2009) 201, 75-80

\section{Introduction}

Preadipocytes are mesenchymal fibroblast-like cells within the stromal compartment of adipose tissue that are committed to the adipocyte lineage (Scadden 2007). Healthy adipose tissue growth and functionality are maintained when differentiation of preadipocytes into adipocytes is coordinated with lipid storage within mature adipocytes.

Obesity, commonly defined as an excess of adipose tissue mass, can also be characterized by the functional status of adipocytes. In particular, insulin resistance and inflammation are features of hypertrophied adipocytes (Schenk et al. 2008). Their prominence in adipose tissue may be a compensatory response for reduced adipogenic capacity when energy balance is chronically positive (Danforth 2000, Heilbronn et al. 2004, Dubois et al. 2006). Preventing the decrease in adipocyte differentiation is therefore a potential therapeutic target to restore insulin sensitivity, and learning more about signaling pathways activated by anti-adipogenic factors may be informative.

Platelet-derived growth factor (PDGF) is a negative regulator of adipogenesis (Hauner et al. 1995, Krieger-Brauer \& Kather 1995, Artemenko et al. 2005). PDGF receptor (PDGFR) mRNA and protein levels fall during 3T3-L1 adipocyte differentiation (Vaziri \& Faller 1996, Summers et al. 1999, Whiteman et al. 2003), and a correlation between PDGFR expression and adipocyte size has also been observed
(Bluher et al. 2004). Recent reports have further highlighted the physiological relevance of PDGF in adipose tissue inflammation (Nishimura et al. 2008, Pang et al. 2008).

To identify anti-adipogenic preadipocyte signaling networks activated by PDGF, we compared preadipocyte responses elicited by PDGF versus insulin, a pro-adipogenic factor (Gagnon et al. 1999). Our data demonstrate that PDGF, but not insulin, activates the inhibitor of $\kappa \mathrm{B}$ kinase $\beta$ (IKK $\beta$ ) in human preadipocytes. Inhibition of this event with an IKK $\beta$ inhibitor curtails the anti-adipogenic action of PDGF, highlighting its importance as a key PDGF signaling response in these cells.

\section{Materials and Methods}

Culture of 3T3-L1 preadipocytes and screening of activated kinases

3T3-L1 preadipocytes were grown to confluence in Dulbecco's Modified Eagle's Medium (DMEM) supplemented with $10 \%$ calf serum, $100 \mathrm{U} / \mathrm{ml}$ penicillin, and $0 \cdot 1 \mathrm{mg} / \mathrm{ml}$ streptomycin (all from Invitrogen). Cells were placed in serum-reduced condition overnight prior to 5 -min stimulation with $1 \mu \mathrm{M}$ insulin or $10 \mathrm{ng} / \mathrm{ml}$ PDGF-BB (Calbiochem, San Diego, CA, USA). Cellular lysates were prepared by solubilizing proteins in Laemmli buffer (Laemmli 1970) supplemented with $1 \mathrm{mM}$ sodium orthovanadate, 
$5 \mathrm{mM}$ sodium pyrophosphate, $50 \mathrm{mM}$ sodium fluoride $(\mathrm{NaF})$, and $5 \mathrm{mM}$ EGTA. Samples were sent to Kinexus for analysis of phosphorylated kinases with a Kinetworks phosphosite screen (KCPS-1.0). Alternatively, cellular lysates were processed for immunoblot analysis, as described below.

\section{Isolation and culture of human preadipocytes}

Subcutaneous adipose tissue was obtained from 19 patients (15 women and 4 men) undergoing elective abdominal surgery (approved by The Ottawa Hospital Research Ethics Board). Mean age was $51 \pm 12$ year, and mean body mass index (BMI) was $30 \pm 6 \mathrm{~kg} / \mathrm{m}^{2}$ ( \pm s.D.; range from 22 to $48 \mathrm{~kg} / \mathrm{m}^{2}$ ). We did not detect any obvious effects on IKK $\beta$ related cellular responses associated with this variation in BMI. Preadipocytes were isolated as previously described (Artemenko et al. 2005). Briefly, tissue was separated from connective tissue and capillaries by dissection, then digested with collagenase CLS type I (600 U/g of tissue; Worthington, Lakewood, NJ, USA). The digested tissue was subjected to progressive size filtration and centrifugation, followed by incubation in erythrocyte lysis buffer. Preadipocytes were seeded at a density of $3 \times 10^{4}$ cells $/ \mathrm{cm}^{2}$ and grown to confluence in DMEM supplemented with $10 \%$ fetal bovine serum (Invitrogen), $100 \mathrm{U} / \mathrm{ml}$ penicillin, $0 \cdot 1 \mathrm{mg} / \mathrm{ml}$ streptomycin, and $50 \mathrm{U} / \mathrm{ml}$ nystatin (Calbiochem). Confluent cultures were used either for stimulation or differentiation studies, as described below.

\section{Stimulation of human preadipocytes}

Prior to stimulation, confluent preadipocytes were maintained in DMEM supplemented with $0.5 \%$ calf serum and antibiotics for 16-20 h. Cells were placed in Krebs-RingerHEPES (KRH) buffer (Gagnon et al. 1999), and stimulated at $37^{\circ} \mathrm{C}$ with $1 \mu \mathrm{M}$ insulin, $5-20 \mathrm{ng} / \mathrm{ml}$ PDGF-BB or vehicle ( $2 \mathrm{mg} / \mathrm{ml} \mathrm{BSA}$ in KRH), for up to $30 \mathrm{~min}$, as indicated. For some experiments, cells were pretreated for $1 \mathrm{~h}$ with $100 \mu \mathrm{M}$ sc-514 (Calbiochem), for $15 \mathrm{~min}$ with $100 \mathrm{nM}$ wortmannin (Kamiya Biochemical Company, Seattle, WA, USA), or vehicle $(0 \cdot 1 \%$ DMSO $)$ prior to stimulation, as indicated. Proteins were solubilized in Laemmli buffer (Laemmli 1970) supplemented with $1 \mathrm{mM}$ sodium orthovanadate, $5 \mathrm{mM}$ sodium pyrophosphate, $50 \mathrm{mM} \mathrm{NaF}$, and $5 \mathrm{mM}$ EGTA.

\section{Differentiation of human preadipocytes}

Confluent human preadipocytes were pretreated for $15 \mathrm{~min}$ with $100 \mu \mathrm{M} \mathrm{sc}-514$ (Calbiochem) or $0 \cdot 1 \%$ DMSO prior to induction of differentiation. Differentiation was induced as previously described (Artemenko et al. 2005) by supplementing the medium with $5 \mu \mathrm{g} / \mathrm{ml}$ insulin, $100 \mu \mathrm{M}$ indomethacin, $0.5 \mu \mathrm{M}$ dexamethasone, and $0.25 \mathrm{mM}$ isobutylmethylxanthine in the presence or absence of $10 \mathrm{ng} / \mathrm{ml}$ PDGF-BB, and either $100 \mu \mathrm{M}$ sc -514 or $0 \cdot 1 \%$ DMSO. After 12 to 15 days, cultures were photographed with a Nikon Coolpix 995 digital camera mounted on a Nikon Eclipse TS100 microscope. Cells were washed, and triacylglycerol (TG) was extracted and quantified spectrophotometrically (Gagnon et al. 1999). Proteins were solubilized in Laemmli buffer (Laemmli 1970) and used in immunoblot analysis.

\section{Immunoblot analysis}

Equal amounts of protein (5-25 $\mu \mathrm{g}$ depending on the experiment) were resolved by SDS-PAGE and transferred to a nitrocellulose membrane. Non-specific binding sites were blocked and membranes were incubated with antibodies specific for actin $(0.4 \mu \mathrm{g} / \mathrm{ml}$; Santa Cruz Biotech., Santa Cruz, CA, USA), AKT (clone C-20; $2 \mu \mathrm{g} / \mathrm{ml}$; Santa Cruz Biotech.), fatty acid synthase (FAS; $1.0 \mu \mathrm{g} / \mathrm{ml}$; BD Biosciences, Mississauga, $\mathrm{ON}$, Canada), inhibitor of $\kappa \mathrm{B} \alpha(\mathrm{I} \kappa \mathrm{B} \alpha$; 1:1000), IKK $\beta$ (1:500), phospho-AKT Ser473 (pAKT; 1:1000), or phospho-IKK (pIKK; 1:500), all from Cell Signaling (Danvers, MA, USA).

\section{Preparation of nuclear extracts and NF- $\kappa B D N A$-binding assay}

Human abdominal s.c. preadipocytes were placed in DMEM supplemented with $1 \%$ calf serum and antibiotics. Cells were pretreated with either $100 \mu \mathrm{M} \mathrm{sc}-514$ or $0 \cdot 1 \%$ DMSO for $1 \mathrm{~h}$, then treated with or without $10 \mathrm{ng} / \mathrm{ml}$ PDGF for $30 \mathrm{~min}$. Cells were washed twice with ice-cold PBS/phosphatase inhibitor buffer, then placed in $20 \mathrm{mM}$ Hepes, $\mathrm{pH}$ 7.5, $5 \mathrm{mM} \mathrm{NaF}, 10 \mu \mathrm{M} \mathrm{Na}_{2} \mathrm{MoO}_{4}$, and $0 \cdot 1 \mathrm{mM}$ EDTA, and allowed to swell. Nonidet P-40 was added to a final concentration of $0.5 \%$, then the homogenates were centrifuged at $14000 \mathrm{~g}$ for $1 \mathrm{~min}$ at $4{ }^{\circ} \mathrm{C}$. Nuclear pellets were then processed for NF- $\kappa \mathrm{B}$ DNA-binding activity using the TransAM NF- $\kappa B$ kit (Active Motif, Carlsbad, CA, USA), according to the manufacturer's instructions. A nuclear fraction prepared from activated Jurkat cells, provided with the kit, was used as a positive control for the assay.

\section{Statistical analyses}

ANOVA was performed, followed by the Newman-Keul's test to assess differences between means (Instat, version 3.05; GraphPad, San Diego, CA, USA) $P$ values $<0.05$ were considered significant.

\section{Results}

IKK $\beta$ phosphorylation occurs in response to PDGF, but not insulin, in 3T3-L1 and human preadipocytes

In a search for intracellular targets differentially regulated by insulin and PDGF, 3T3-L1 preadipocytes were stimulated for 5 min with insulin or PDGF. A commercial phosphokinase screen of cellular lysates by Kinexus was conducted. Whereas the phosphorylation of some kinases in response to PDGF 
versus insulin was similar, the phosphorylation of IKK $\beta$ was 12.4-fold higher in PDGF- versus insulin-treated 3T3-L1 preadipocytes (Fig. 1A). We confirmed this large differential signaling response in 3T3-L1 preadipocytes, and demonstrated that it also occurred in primary human abdominal s.c. preadipocytes (Fig. 1B). Treatment with $10 \mathrm{ng} / \mathrm{ml}$ PDGF for $5 \mathrm{~min}$ increased IKK $\beta$ phosphorylation by 20-fold $(P<0 \cdot 001)$ and $7 \cdot 6$-fold $(P<0 \cdot 01)$, compared with basal, in 3T3-L1 and human preadipocytes respectively. Treatment with $1 \mu \mathrm{M}$ insulin failed to increase IKK $\beta$ phosphorylation.

IKK $\beta$ phosphorylation by PDGF depends on phosphatidylinositol (PI) 3-kinase

To further characterize the regulation of IKK $\beta$ by PDGF, human preadipocytes were treated with insulin or PDGF for the indicated times. IKK $\beta$ phosphorylation was transiently stimulated by PDGF, with a 16-fold increase within $5 \mathrm{~min}$ of exposure $(P<0 \cdot 001)$, which returned to basal levels within $30 \mathrm{~min}$ (Fig. 2A). IKK $\beta$ phosphorylation in response to insulin was not observed at any of the times tested. Maximal IKK $\beta$ phosphorylation was observed at a dose of $5 \mathrm{ng} / \mathrm{ml}$ PDGF (Fig. 2B). Pretreatment with wortmannin, a specific PI3kinase inhibitor, significantly reduced PDGF-induced IKK $\beta$ phosphorylation by $60 \%(P<0 \cdot 05)$, implicating the PI3kinase/AKT pathway in this regulation (Fig. 2C). Insulin, like PDGF, also stimulated AKT phosphorylation, but did not have a significant effect on IKK $\beta$ phosphorylation.

PDGF-induced IKK $\beta$ phosphorylation does not lead to the degradation of $I \kappa B \alpha$ and activation of $N F-\kappa B$

To investigate downstream signaling events beyond PDGFstimulated IKK $\beta$ phosphorylation, we assessed the degradation of $I \kappa B \alpha$ and activation of $N F-\kappa B$, known consequences of IKK $\beta$ activation. However, the levels of $\mathrm{I} \kappa \mathrm{B} \alpha$ were unchanged in PDGF-treated human preadipocytes. Consistent with this observation, PDGF failed to activate NF- $\mathrm{B}$, assessed by DNA binding to an NF- $\mathrm{NB}-$ specific response element.

\begin{tabular}{|l|c|c|}
\hline Ainase & \multicolumn{2}{|c|}{ Corrected trace quantity (cpm) } \\
(phosphorylation site) & Insulin & PDGF \\
\hline IKK $\alpha$ (S180) & N.D. & N.D. \\
IKK $\beta$ (S181) & 152 & 1887 \\
Focal adhesion kinase (S722) & 3579 & 3501 \\
p70 S6 kinase (T389) & 965 & 1001 \\
\hline
\end{tabular}
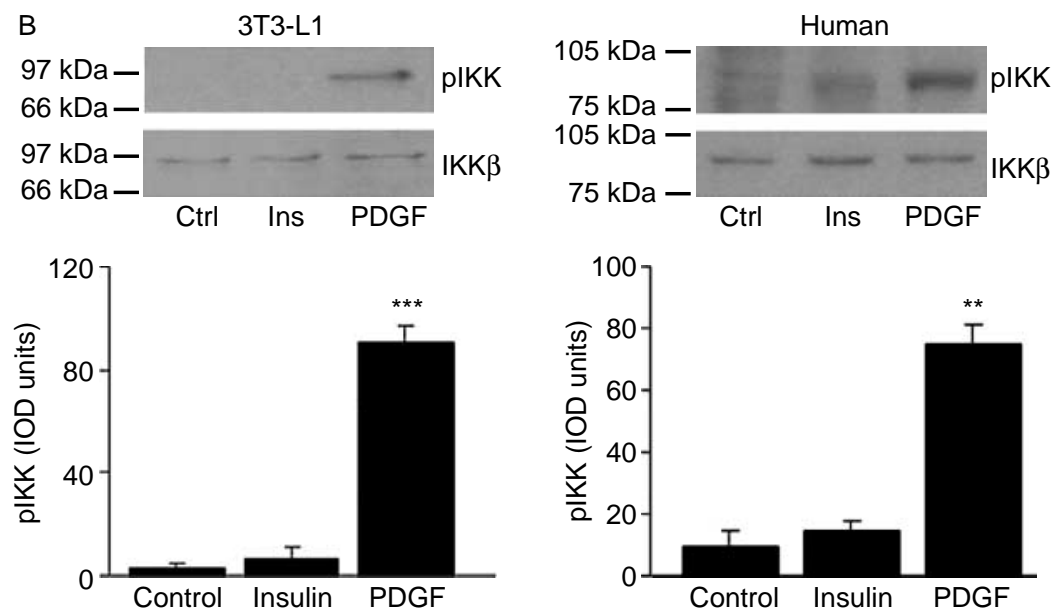

Figure 1 PDGF, but not insulin, induces IKK $\beta$ phosphorylation in 3T3-L1 and human abdominal s.c. preadipocytes. Confluent 3T3-L1 or human preadipocytes were placed in medium supplemented with $0 \cdot 5 \%$ calf serum overnight prior to stimulation. Cells were stimulated for $5 \mathrm{~min}$ with $1 \mu \mathrm{M}$ insulin (Ins), $10 \mathrm{ng} / \mathrm{ml}$ PDGF, or vehicle control (Ctrl). (A) Cellular lysates from 3T3-L1 preadipocytes were processed for phosphokinase analysis as described. The intensity of the bands was quantified and is reported as counts per minute (cpm) for the indicated kinases. N.D., not detectable. (B) Equal amounts of solubilized protein from 3T3-L1 or human preadipocytes were immunoblotted with the indicated antibodies. Representative immunoblots from one experiment or patient sample are shown. Densitometric data from three independent experiments or three separate patient samples are expressed as means \pm S.E.M. Statistical significance is indicated as $* * * P<0 \cdot 001$ or $* * P<0 \cdot 01$ compared with control and insulin-treated conditions. IOD, integrated optical density. 


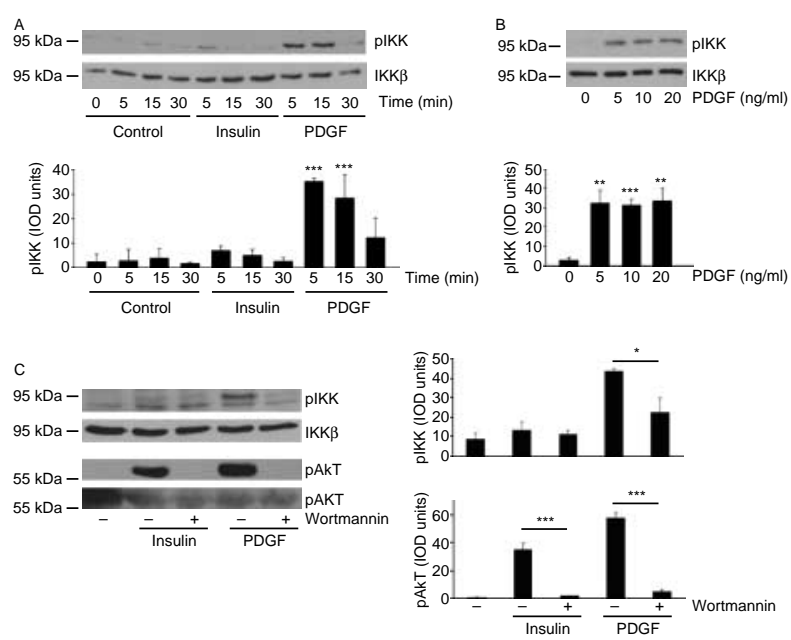

Figure 2 PDGF induces IKK $\beta$ phosphorylation in human abdominal s.c. preadipocytes via activation of PI3-kinase. Confluent human preadipocytes were placed in medium supplemented with $0.5 \%$ calf serum overnight prior to stimulation. (A) Cells were stimulated with $1 \mu \mathrm{M}$ insulin, $10 \mathrm{ng} / \mathrm{ml} \mathrm{PDGF}$, or vehicle control for the indicated times. (B) Cells were stimulated with 0-20 ng/ml PDGF for $5 \mathrm{~min}$. (C) Cells were pretreated with $100 \mathrm{nM}$ wortmannin or vehicle $(0 \cdot 1 \%$ DMSO) for $15 \mathrm{~min}$, then stimulated for 5 min with $1 \mu \mathrm{M}$ insulin or $10 \mathrm{ng} / \mathrm{ml}$ PDGF. Equal amounts of solubilized protein were immunoblotted with the indicated antibodies. Representative immunoblots from a single patient sample are shown. Densitometric data from three separate patient samples are expressed as means \pm S.E.M. Statistical significance is indicated as $* * * P<0 \cdot 001,{ }^{* *} P<0 \cdot 01$, or $* P<0.05$ compared with control and insulin-treated conditions, or as indicated. IOD, integrated optical density.

\section{Sc-514 reverses the anti-adipogenic effect of PDGF on human adipogenesis}

We examined the functional role of IKK $\beta$ with respect to PDGF-mediated inhibition of adipogenesis. Human abdominal s.c. preadipocytes were treated with sc-514, a selective inhibitor of IKK $\beta$ (Kishore et al. 2003), for $15 \mathrm{~min}$, followed by induction of differentiation, either in the presence or absence of $10 \mathrm{ng} / \mathrm{ml}$ PDGF. As previously reported (Artemenko et al. 2005), PDGF treatment strongly reduced the morphological changes that characteristically occur during adipocyte differentiation, including the accumulation of lipid droplets (Fig. 3A). The inhibitory effect of PDGF on lipid droplet accumulation was nullified by sc-514. These morphological effects were quantified by measuring cellular TG content (Fig. 3B). TG accumulation was reduced by $75 \%$ $(P<0 \cdot 01)$ in response to PDGF, but when sc-514 was present, the inhibition by PDGF was only $28 \%$, and was no longer significant. Consistent with this response, the protein expression of FAS, an adipogenic marker, was reduced by $60 \%(P<0 \cdot 05)$ in the presence of PDGF, but with sc-514 present, the inhibition by PDGF was attenuated to $23 \%$, and no longer reached significance (Fig. 3C). There was no significant effect on either FAS expression or TG accumulation with sc-514 alone.

\section{Discussion}

PDGF is a growth factor that is known to be anti-adipogenic (Hauner et al. 1995, Krieger-Brauer \& Kather 1995, Artemenko et al. 2005). PDGFR expression is regulated according to the stage of adipocyte differentiation as well as by adipocyte cell size (Vaziri \& Faller 1996, Summers et al. 1999, Whiteman et al. 2003, Bluher et al. 2004). Here, we demonstrate that IKK $\beta$ is activated by PDGF in human preadipocytes, and that it is required for the inhibition of adipogenesis by PDGF. IKK $\beta$ was phosphorylated by PDGF, but not by insulin, a pro-adipogenic agent.

Only a few other studies have linked the IKK $\beta / N F-\kappa B$ pathway to PDGF signaling and responses in other cell types. $\mathrm{NF}-\kappa \mathrm{B}$ participates in the regulation of PDGF-inducible genes and cell transformation in mouse fibroblasts (Olashaw et al. 1992). In addition, anti-apoptotic and proliferative responses by human skin fibroblasts and rat synoviocytes induced by PDGF depend on IKK $\beta / N F-\kappa B$ (Romashkova $\&$ Makarov 1999). To our knowledge, this is the first study reporting the regulation of this pro-inflammatory pathway in human adipose cells.

The phosphorylation of IKK $\beta$ observed in response to PDGF treatment of human preadipocytes was not accompanied by degradation of $\mathrm{I} \kappa \mathrm{B} \alpha$ or activation of $\mathrm{NF}-\kappa \mathrm{B}$. Although infrequent, activation of IKK $\beta$, without concomitant $N F-\kappa B$ activation was recently shown to occur with respect to the regulation of interferon- $\gamma$-dependent genes (Tudhope et al. 2007). IKK $\beta$ has also been reported to directly phosphorylate substrates such as IRS-1 (on serine residue 307/312; rodent/human), as well as FOXO3, and 14-33b (Perkins 2007); these proteins have been implicated in the regulation of adipose tissue function (Miki et al. 2001, Hong et al. 2005, Luo et al. 2008). Further research will be needed to evaluate the possible roles of each of these candidate proteins with respect to the PDGF-mediated anti-adipogenic effect we have observed here.

The role of the PI3-kinase/AKT pathway in the activation of IKK $\beta$ has been noted in other cells (Parhar et al. 2007, Dan et al. 2008). It has been demonstrated that AKT and IKK $\beta$ associate in response to PDGF (Romashkova \& Makarov 1999). However, it is unclear why insulin, which also activates AKT in human preadipocytes, does not lead to IKK $\beta$ phosphorylation. We have previously shown that antiadipogenic PDGF generates both PI(3,4)P2 and $\mathrm{PI}(3,4,5) \mathrm{P} 3$, while pro-adipogenic insulin leads to accumulation of only $\mathrm{PI}(3,4,5) \mathrm{P} 3$ in preadipocytes (Sorisky et al. 1996, Gagnon et al. 1999). This differential generation of 3-phosphoinositides by these two agonists may alter the activation characteristics of AKT or its cellular compartmentalization, leading to the activation/phosphorylation of distinct arrays of substrates that may differentially modulate the activation of IKK $\beta$. It is also possible that other, as yet unidentified, upstream regulatory molecules play a role in PDGF-stimulated IKK $\beta$ phosphorylation. 

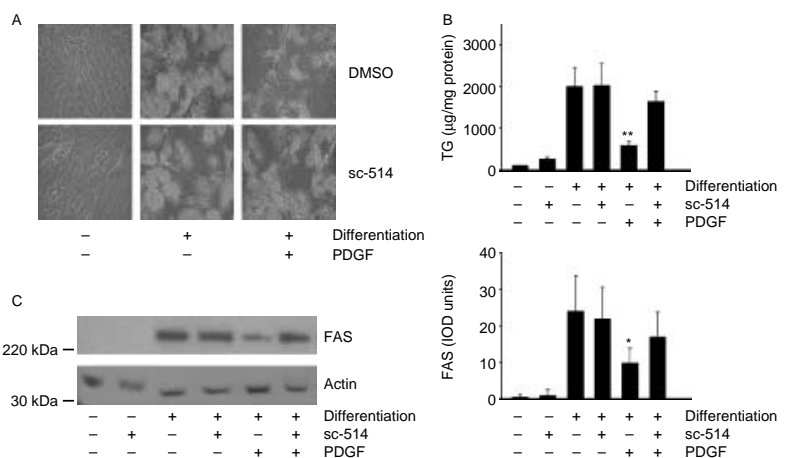

Figure 3 Sc-514 reverses the anti-adipogenic action of PDGF on human s.c. abdominal preadipocyte differentiation. Human preadipocytes were pretreated for 15 min with $100 \mu \mathrm{M}$ sc-514 prior to induction of differentiation in the presence or absence of $10 \mathrm{ng} / \mathrm{ml}$ PDGF for 14 days. (A) Cultures were photographed at $400 \times$ magnification. Representative microphotographs from a single patient sample are shown. (B) TG was extracted, quantified, and normalized to protein content. Results are expressed as the mean \pm s.D. of five patient samples. ${ }^{* *}$ indicates $P<0 \cdot 01$ compared with other differentiated conditions. (C) Solubilized proteins were immunoblotted with antibodies against FAS or actin (used as a loading control). Representative immunoblots from a single patient sample are shown. (D) Densitometric data from the five patient samples are expressed as mean \pm s.D. ${ }^{*}$ indicates $P<0.05$ compared with other differentiated conditions. IOD, integrated optical density.

Previous studies have examined PDGF and preadipocytes to determine which downstream signaling events are involved in its ability to inhibit adipogenesis. Conventional protein kinase $\mathrm{C}$ (PKCs) have been implicated in studies investigating the anti-adipogenic effect of PDGF on human preadipocytes (Artemenko et al. 2005), and conventional PKCs, ERK1/2, and NADPH-dependent $\mathrm{H}_{2} \mathrm{O}_{2}$ generation have been reported using 3T3-L1 preadipocytes (Krieger-Brauer \& Kather 1995, Camp \& Tafuri 1997, Artemenko et al. 2005). At present, the precise relationship between these signaling events in preadipocytes and the activation of the IKK $\beta$ pathway is unknown, but merits attention.

Our studies with the pharmacological inhibitor sc-514 suggest that IKK $\beta$ participates in the anti-adipogenic effects of PDGF. Sc-514 has been shown to be a potent inhibitor of IKK $\beta$, with ten times more selectivity for IKK $\beta$ than many other kinases stimulated by PDGF, including ERKs, p38 MAPK, and conventional PKCs (Kishore et al. 2003). Further studies, such as RNA silencing, would nonetheless complement these findings.

In summary, our data reveal a pro-inflammatory signaling response that is a required element for the anti-adipogenic effect of PDGF on human preadipocytes.

\section{Declaration of interest}

The authors declare that there is no conflict of interest that would prejudice the impartiality of this scientific work.

\section{Funding}

This work was supported by Canadian Institutes for Health Research (grant no. MOP-43850).

\section{Acknowledgements}

We thank the surgeons and patients of the Ottawa Hospital for their help in acquiring the adipose tissue samples for this study.

\section{References}

Artemenko Y, Gagnon A, Aubin D \& Sorisky A 2005 Anti-adipogenic effect of PDGF is reversed by PKC inhibition. Journal of Cellular Physiology 204 646-653.

Bluher M, Patti M-E, Gesta S, Kahn BB \& Kahn CR 2004 Intrinsic heterogeneity in adipose tissue of fat-specific insulin receptor knock-out mice is associated with differences in patterns of gene expression. Journal of Biological Chemistry 279 31891-31901.

Camp HS \& Tafuri SR 1997 Regulation of peroxisome proliferator-activated receptor $\gamma$ activity by mitogen-activated protein kinase. Journal of Biological Chemistry 272 10811-10816.

Dan HC, Cooper MJ, Cogswell PC, Duncan JA, Ting JP, Baldwin AS \& Heufelder AE 2008 Akt-dependent regulation of NF- $\kappa \mathrm{B}$ is controlled by mTOR and Raptor in association with IKK. Genes and Development 22 1490-1500.

Danforth E Jr 2000 Failure of adipocyte differentiation causes type 2 diabetes mellitus? Nature Genetics 2613.

Dubois SG, Heilbronn LK, Smith SR, Albu JB, Kelley DE, Ravussin E \& the Look AHEAD Adipose Research Group 2006 Decreased expression of adipogenic genes in obese subjects with type 2 diabetes. Obesity 14 1543-1552.

Gagnon A, Chen C-S \& Sorisky A 1999 Activation of protein kinase B and induction of adipogenesis by insulin in 3T3-L1 preadipocytes. Contribution of phosphoinositide-3,4,5-trisphosphate versus phosphoinositide3,4-bisphosphate. Diabetes 48 691-698.

Hauner H, Rohrig K \& Petruschke T 1995 Effects of epidermal growth factor (EGF), platelet-derived growth factor (PDGF) and fibroblast growth factor (FGF) on human adipocyte development and function. European Journal of Clinical Investigation 25 90-96.

Heilbronn L, Smith SR \& Ravussin E 2004 Failure of fat cell proliferation, mitochondrial function and fat oxidation results in ectopic fat storage, insulin resistance and type 2 diabetes mellitus. International Journal of Obesity 28 S12-S21.

Hong JH, Hwang ES, McManus MT, Amsterdam A, Tian Y, Kalmukova R, Mueller E, Benjamin T, Spiegelman BM, Sharp PA et al. 2005 TAZ, a transcriptional modulator of mesenchymal stem cell differentiation. Science 309 1074-1078.

Kishore N, Sommers C, Mathialagan S, Guzova J, Yao M, Hauser S, Huyn K, Bonar S, Mielke C, Albee L et al. 2003 A selective IKK-2 inhibitor blocks NF- $\kappa \mathrm{B}$-dependent gene expression in interleukin-1 $\beta$-stimulated synovial fibroblasts. Journal of Biological Chemistry 278 32861-32871.

Krieger-Brauer HI \& Kather H 1995 Antagonistic effects of different members of the fibroblast and platelet-derived growth factor families on adipose conversion and NADPH-dependent $\mathrm{H} 2 \mathrm{O} 2$ generation in 3T3-L1 cells. Biochemical Journal 307 549-556.

Laemmli UK 1970 Cleavage of structural proteins during the assembly of the head of bacteriophage T4. Nature 227 680-685.

Luo W, Cao J, Li J \& He W 2008 Adipose tissue-specific PPAR $\gamma$ deficiency increases resistance to oxidative stress. Experimental Gerontology 43 154-163.

Miki H, Yamauchi T, Suzuki R, Komeda K, Tsuchida A, Kubota N, Terauchi Y, Kamon J, Kaburagi Y, Matsui J et al. 2001 Essential role of insulin receptor substrate 1 (IRS-1) and IRS-2 in adipocyte differentiation. Molecular and Cellular Biology 21 2521-2532.

Nishimura S, Manabe I, Nagasaki M, Seo K, Yamashita H, Hosoya Y, Ohsugi M, Tobe K, Kadowaki T, Nagai R et al. 2008 In vivo imaging in mice reveals local cell dynamics and inflammation in obese adipose tissue. Journal of Clinical Investigation 118 710-721. 
Olashaw NE, Kowalik TF, Huang E-S \& Pledger WJ 1992 Induction of NF- $\mathrm{KB}$-like activity by platelet-derived growth factor in mouse fibroblasts. Molecular Biology of the Cell 3 1131-1139.

Pang C, Gao Z, Yin J, Zhang J, Jia W \& Ye J 2008 Macrophage infiltration into adipose tissue may promote angiogenesis for adipose tissue remodeling in obesity. American Journal of Physiology. Endocrinology and Metabolism 295 313-322.

Parhar K, Eivemark S, Assi K, Gomez-Munoz A, Yee A \& Salh B 2007 Investigation of interleukin $1 \beta$-mediated NF- $\mathrm{KB}$ activation in colonic cells reveals divergence between PKB and PDK-transduced events. Molecular and Cellular Biochemistry 300 113-127.

Perkins ND 2007 Integrating cell-signalling pathways with NF- $\kappa B$ and IKK function. Nature Reviews. Molecular Cell Biology 8 49-62.

Romashkova JA \& Makarov SS 1999 NF-KB is a target of Akt in antiapoptotic PDGF signalling. Nature $40186-90$.

Scadden DT 2007 The weight of cell identity. Journal of Clinical Investigation 117 3653-3655.

Schenk S, Saberi M \& Olefsky JM 2008 Insulin sensitivity: modulation by nutrients and inflammation. Journal of Clinical Investigation 118 2992-3002.

Sorisky A, Pardasani D \& Lin Y 1996 The 3-phosphorylated phosphoinositide response of 3T3-L1 preadipose cells exposed to insulin, insulin-like growth factor-1, or platelet-derived growth factor. Obesity Research 4 9-19.
Summers SA, Whiteman EL, Cho H, Lipfert L \& Birnbaum MJ 1999 Differentiation-dependent suppression of platelet-derived growth factor signaling in cultured adipocytes. Journal of Biological Chemistry 274 23858-23867.

Tudhope SJ, Catley MC, Fenwick PS, Russell RE, Rumsey WL, Newton R, Barnes PJ \& Donnelly LE 2007 The role of IKB kinase 2, but not activation of NF- $\kappa \mathrm{B}$ in the release of CXCR 3 ligands from IFN- $\gamma$-stimulated human bronchial epithelial cells. Journal of Immunology 179 6237-6245.

Vaziri C \& Faller DV 1996 Down-regulation of platelet-derived growth factor receptor expression during terminal differentiation of 3T3-L1 preadipocyte fibroblasts. Journal of Biological Chemistry 271 13642-13648.

Whiteman EL, Chen JJ \& Birnbaum MJ 2003 Platelet-derived growth factor (PDGF) stimulates glucose transport in 3T3-L1 adipocytes overexpressing PDGF receptor by a pathway independent of insulin receptor substrates. Endocrinology 144 3811-3820.

Received in final form 15 December 2008

Accepted 13 January 2009

Made available online as an Accepted Preprint 13 January 2009 